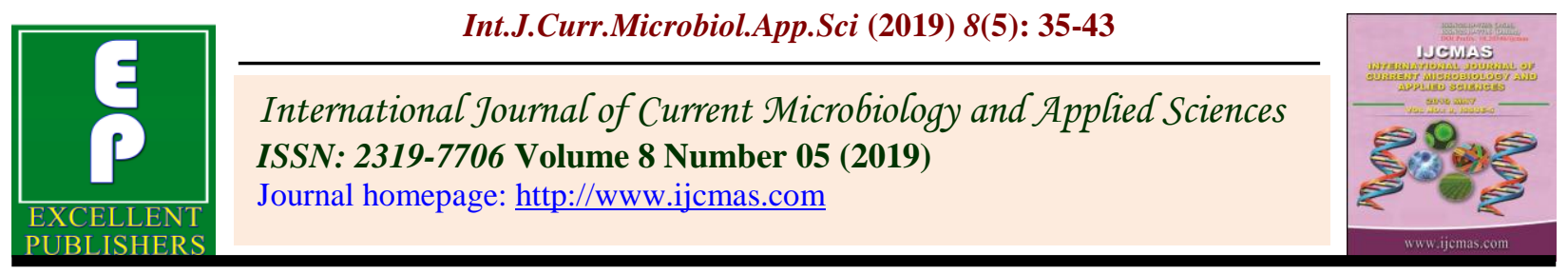

\title{
A Study on Extended Spectrum Beta Lactamse and Amp C Beta Lactamse Producing Enterobacteriaceae Isolates from Various Clinical Samples in a Tertiary Care Hospital
}

\author{
Radhika Katragadda $^{1}$, Sowmya A. Venkateswaran ${ }^{1}$ and J. Padmakumari ${ }^{2}$ \\ ${ }^{1}$ Department of Microbiology, Government Medical College, Omandurar Govt. Estate, \\ Chennai-2, Tamil Nadu, India \\ ${ }^{2}$ Institute of Microbiology, Madras Medical College, Chennai, Tamil Nadu, India \\ *Corresponding author
}

\begin{tabular}{|l|}
\hline Ke y w o r d s \\
Enterobacteriaceae, \\
ESBL, Amp C \\
\hline Article Info \\
\hline $\begin{array}{l}\text { Accepted: } \\
\text { 04 April } 2019 \\
\text { Available Online: } \\
\text { 10 May } 2019\end{array}$ \\
\hline
\end{tabular}

A B S T R A C T

Over the period of years infections caused by multidrug resistance organisms has emerged as a major public health problem. Their prevalence rates vary in different parts of the world and hence local data regarding these pathogens were important. Our study was aimed to identify the presence of ESBL and AmpC producing Enterobacteriaceae isolates from various clinical samples in our hospital setup various clinical samples were processed consecutively during the study period for microbiological analysis as per standard operating procedure. Enterobacteriaceae isolates were further tested by phenotypic confirmatory methods for ESBL and AmpC production, as per CLSI guidelines. Out of 1583 samples processed, 522 samples were culture positives $(32.97 \%)$. $74.52 \%$ of isolates belongs to Enterobacteriaceae family. Most common Enterobacteriaceae isolate was E.coli (42.42\%) followed by Klebsiella species (41.90\%) and Proteus species (11.06\%). Among the total 389 Enterobacteriaceae isolates 152(39.07\%) were ESBL producers and 8(2.11\%) were Amp C producers. E.coli and Klebsiella species were the most common ESBL producing isolates $(41.45 \%$ each), whereas the majority of AmpC producers were K.pneumoniae (75\%). Early detection and proper management of infections caused by these MDR organisms are very important in preventing their emergence and spread. Time to time knowledge about their prevalence and their antibiotic resistance pattern can become a powerful tool in handling infections caused by them.

\section{Introduction}

Over the last two decades, infections caused by multidrug resistance (MDR) organisms have emerged as a major public health problem, especially with those that have become resistance to third generation cephalosporins and carbapenems. Their widespread global dissemination has become a significant problem worldwide. Enterobacteriaceae group of Gram negative bacteria, are the most common bacteria's isolated from majority of clinical samples. Antibiotic resistance among these group of bacteria is a rapidly emerging problem in public health sector, as they are capable to 
acquire, transmit and mutate plasmids and other mobile genetic elements carrying antimicrobial resistance genes among each other and also among closely related bacteria's with ease (Binita Bhuyan et al, 2018).

The detection of antibiotics by our pioneers was a great boon to mankind, which protected us from infections. However bacteria's were constantly evolving and developing various strategies to become immune against the cidal effects of antimicrobial agents. One of the important mechanisms of antimicrobial resistance was the production of certain enzymes by the bacteria, which can inhibit or destroy the action of antimicrobial drugs. Among Gram negative bacteria production of beta lactamases, especially extended spectrum beta lactamases (ESBLs), Metallo betalactamases (MBLs) and AmpC production has emerged as a major cause of antimicrobial resistance (Pfeifer Y et al., 2010). Infections caused by such multidrug resistance bacteria pose significant threat to treating clinician and also to patients, by means of prolonged hospital stay, high health care costs and high mortality and morbidity rates.

ESBLs are beta lactamases producing bacteria that belong to Group 2be of Bush-JacobyMedeiros classification. They work by hydrolyzing the beta lactam ring of beta lactam antibiotics, like cephalosporins, aztreonam etc. They are inhibited by using beta-lactamase inhibitors like sulbactam, tazobactam, clavulanic acid (Rawat et al., 2010). AmpC beta-lactamases are well defined enzymes, belonging to group 1 of Bush-Jacoby-Medeiros classification. These enzymes, both chromosomal and plasmid mediated show an action spectrum similar to ESBLs. However they are not inhibited by beta lacatmase inhibitors and they respond to carbapenem group of drugs (Tamang et al., 2012). This study was conducted to analyse the presence of ESBL producing and AmpC producing Enterobacteriaceae isolates from various clinical samples in our tertiary care centre.

\section{Materials and Methods}

The study was conducted after getting Institutional Ethical Committee approval. During the three months study period various consecutive samples like urine, pus, throat swabs, wound swabs, body fluids, sputum and blood received for culture and sensitivity were processed according to standard operating guidelines. Samples were inoculated onto Nutrient agar, MacConkey agar and Blood agar plates by sterile technique. The inoculated plates were incubated at $37^{\circ} \mathrm{C}$ overnight and the resultant colonies were identified using Gram's stain and conventional biochemical reactions like catalase, oxidase, oxidation -fermentation test, triple sugar iron test, citrate test and urease test. Antibiotic sensitivity testing of the isolates was carried out by modified Kirby Bauer disc diffusion technique, according to CLSI guidelines. Isolates belonging to Enterobacteriaceae family were further tested along with appropriate controls for the production of extended spectrum beta lactamase (ESBL) and AmpC enzymes as per CLSI guidelines 2017.

\section{Detection of ESBL production}

Enterobacteriaceae isolates which showed resistance to cefotaxime $(30 \mu \mathrm{g})(\leq 27 \mathrm{~mm})$ were presumptively identified as ESBL producers and confirmed by phenotypic combined double disc diffusion testing method. 0.5 McFarland suspension of the isolate was inoculated onto Mueller Hinton agar. Cefotaxime $(30 \mu \mathrm{g})$ disc and cefotaxime + clavulanic $(30 / 10 \mu \mathrm{g})$ disc were placed on the surface of the inoculum at $20 \mathrm{~mm}$ apart. The plates were incubated at $37^{\circ} \mathrm{C}$ overnight. 
A increase of zone of inhibition of $\geq 5 \mathrm{~mm}$ in the combined disc (cefotaxime + clavulanic $(30 / 10 \mu \mathrm{g})$ when compared to cefotaxime disc $(30 \mu \mathrm{g})$ were confirmed as ESBL producers. The sensitivity and specificity range of this double disc diffusion testing ranges from $79 \%$ to $97 \%$ and $94 \%$ to $100 \%$ respectively (Randegger C et al, 2001) (Vercauteren E et al., 1997).

\section{Detection of Amp C production}

Enterobacteriaceae isolates which showed resistance to cefoxitin $(30 \mu \mathrm{g})(\leq 14 \mathrm{~mm})$ as tested by Kirby Bauer disc diffusion technique, were presumptively identified as AmpC producers and were further subjected to combined disc assay confirmatory test. 0.5 McFarland suspension of the isolate was inoculated onto Mueller Hinton agar.

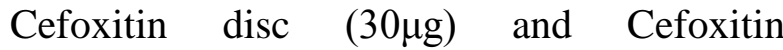
+ Cloxacillin combination disc $(30 \mu \mathrm{g}+200 \mu \mathrm{g})$ were placed onto the surface of the inoculum at $20 \mathrm{~mm}$ apart. The plates were incubated at $37^{\circ} \mathrm{C}$ overnight. An increase of zone of inhibition of $\geq 5 \mathrm{~mm}$ in the combined disc (cefoxitin + cloxacillin $(30 \mu \mathrm{g}+200 \mu \mathrm{g}))$ when compared to cefoxitin disc $(30 \mu \mathrm{g})$ were confirmed as Amp C producers (Rituparna Tewari et al., 2018).

The results were documented and analyzed statistically.

\section{Results and Discussion}

The study was conducted over a period of three months, during which around 1583 varied consecutive clinical samples that were sent to microbiology laboratory for culture and sensitivity testing were included in the study. Out of the total 1583 samples processed, 522 samples came out as culture positives $(32.97 \%)$.

Out of the total culture positives, 389 $(74.52 \%)$ of isolates belongs to
Enterobacteriaceae family, 98 isolates $(18.78 \%)$ were Gram positive organisms and 35 isolates $(6.70 \%)$ were non fermentors.

Most common Enterobacteriaceae isolate was E.coli $(42.42 \%)$ followed by Klebsiella species (41.90\%) and Proteus species $(11.06 \%)$. Majority of the Enterobacteriaceae isolates were from urine samples $(57.58 \%)$ followed by pus samples (32.91\%).

Among the total 389 Enterobacteriaceae isolates $152(39.07 \%)$ were ESBL producers and $8(2.11 \%)$ were Amp C producers.

E.coli and Klebsiella species were the most common ESBL producing isolates $(41.45 \%$ each), whereas the majority of AmpC producers were $K$. pneumoniae $(75 \%)$.

Out of 152 ESBL isolates, $60.53 \%$ were isolated from urine samples followed by pus samples (28.28\%). $75 \%$ of AmpC isolates were from urine samples and the rest of $25 \%$ of Amp C producers were from pus samples.

One of the major concerns in clinical practice, especially in developing countries is the increasing prevalence of infections caused by multidrug resistance organisms. Their prevalence and the type of infections they are associated with vary in different regions of the world owing to the different patterns of antibiotic policies they follow. This study is conducted in our tertiary care hospital to analyse the presence of ESBL and AmpC producing Enterobacteriaceae isolates from varied clinical samples.

Out of the total 1583 samples processed, 522 samples were culture positives (32.97\%). Majority of culture positives were from urine samples $(54.21 \%)$ followed by pus samples $(31.42 \%)$, as urine and pus samples were the most common samples received for Microbiological evaluation, in any tertiary care hospital (Wondemagegn Mulu et al., 
2017). Out of 522 culture isolates, 389 $(74.52 \%)$ belongs to Enterobacteriaceae family, 98 isolates (18.78\%) were Gram positive organisms and 35 isolates $(6.70 \%)$ were non fermenters. Study conducted by Sanjo Gupta et al., (2017), had documented about $60 \%$ of their clinical isolates from varied clinical samples belongs to Enterobacteriaceae group of bacteria, which is less when compared to our study.

The most common Enterobacteriaceae isolate was E.coli $(42.42 \%)$ followed by Klebsiella species (41.90\%) and Proteus species $(11.06 \%)$. Similar studies conducted by Narinder Kaur et al., (2017) and Ashish Jitendranath et al., (2018) also showed that E.coli was the most common isolate $(41.6 \%$, $54 \%$ respectively), followed by Klebsiella species (24\% 32\% respectively). However study conducted by Binita Bhuyan et al., (2018) showed that Klebsiella spp (55.5\%) was the most common isolate among Enterobacteriaceae followed by E.coli (23.9\%).

Among the total 389 Enterobacteriaceae isolates 152 (39.07\%) were ESBL producers. Study conducted by Binita Bhuyan et al (2018) and Narinder Kaur et al., (2017) revealed that about $14.75 \%$ and $25 \%$ of their Enterobacteriaceae isolates were ESBL producers. Whereas study conducted by Sanjo Gupta et al., (2017) had documented 68\% of ESBL producers among Enterobacteriaceae isolates. Various studies conducted in India had documented that the prevalence of ESBL production among various Gram negatives differs from 19.8\%-43\% (Kumar MS et al., 2006).

Table.1 Nature of samples and culture positives

\begin{tabular}{|c|c|c|c|c|}
\hline \multirow{2}{*}{ Sample } & \multicolumn{2}{|c|}{$\begin{array}{c}\text { No. of samples processed } \\
(\mathbf{n = 1 5 8 3})\end{array}$} & \multicolumn{2}{c|}{$\begin{array}{c}\text { Culture positives } \\
(\mathbf{n = 5 2 2})\end{array}$} \\
\cline { 2 - 5 } & No & $\%$ & No & $\%$ \\
\hline Urine & 839 & 53 & 283 & 54.21 \\
\hline Pus & 321 & 20.28 & 164 & 31.42 \\
\hline Wound swab & 95 & 6 & 25 & 4.79 \\
\hline Sputum & 81 & 5.12 & 22 & 4.22 \\
\hline Blood & 132 & 8.33 & 17 & 3.26 \\
\hline Throat swab & 64 & 4.04 & 9 & 1.72 \\
\hline Body fluids & 51 & 3.23 & 2 & 0.38 \\
\hline Total & 1583 & 100 & 522 & 100 \\
\hline
\end{tabular}

Majority of culture positives were from urine samples (54.21\%) followed by pus samples (31.42\%) 
Table.2 Enterobacteriaceae isolates among various clinical samples $(n=389)$

\begin{tabular}{|c|c|c|c|c|c|c|c|c|c|}
\hline $\begin{array}{l}\text { Sample/ } \\
\text { isolates }\end{array}$ & E.coli & $\begin{array}{c}K . \\
\text { pneumoniae }\end{array}$ & $\begin{array}{c}K . \\
\text { oxytoca }\end{array}$ & $\begin{array}{c}E . \\
\text { aerogenes }\end{array}$ & $\begin{array}{c}\text { Citrobacter } \\
\text { sp. }\end{array}$ & $\begin{array}{c}P . \\
\text { mirabilis }\end{array}$ & $\begin{array}{c}P . \\
\text { vulgaris }\end{array}$ & $\begin{array}{c}\text { Providencia } \\
\text { sp. }\end{array}$ & Total \\
\hline Urine & 101 & 66 & 28 & 5 & 1 & 8 & 13 & 2 & $\begin{array}{c}224 \\
(57.58 \%)\end{array}$ \\
\hline Pus & 53 & 37 & 12 & 5 & 2 & 14 & 5 & - & $\begin{array}{c}128 \\
(32.91 \%)\end{array}$ \\
\hline $\begin{array}{l}\text { Wound } \\
\text { swab }\end{array}$ & 10 & 1 & 3 & 1 & - & 3 & - & - & $\begin{array}{c}18 \\
(4.63 \%)\end{array}$ \\
\hline Sputum & - & 8 & 3 & - & 1 & - & - & - & $\begin{array}{c}12 \\
(3.09 \%)\end{array}$ \\
\hline Blood & 1 & 2 & 1 & - & - & - & - & - & $\begin{array}{c}4 \\
(1.03 \%)\end{array}$ \\
\hline $\begin{array}{c}\text { Throat } \\
\text { swab }\end{array}$ & - & 2 & - & - & - & - & - & - & $\begin{array}{c}2 \\
(0.51 \%)\end{array}$ \\
\hline $\begin{array}{l}\text { Body } \\
\text { fluids }\end{array}$ & - & - & - & 1 & - & - & - & - & $\begin{array}{c}1 \\
(0.25 \%)\end{array}$ \\
\hline Total & $\begin{array}{c}165 \\
(42.42 \%)\end{array}$ & $\begin{array}{c}116 \\
(29.82 \%)\end{array}$ & $\begin{array}{c}47 \\
(12.08 \%)\end{array}$ & $\begin{array}{c}12 \\
(3.08 \%)\end{array}$ & $\begin{array}{c}4 \\
(1.03 \%)\end{array}$ & $\begin{array}{c}25 \\
(6.43 \%)\end{array}$ & $\begin{array}{c}18 \\
(4.63 \%)\end{array}$ & $\begin{array}{c}2 \\
(0.51 \%)\end{array}$ & $\begin{array}{c}389 \\
(100 \%)\end{array}$ \\
\hline
\end{tabular}

Table.3 ESBL and Amp C producing Enterobacteriaceae isolates

\begin{tabular}{|l|c|c|c|c|}
\hline \multirow{2}{*}{ Isolates } & \multicolumn{2}{|c|}{$\begin{array}{c}\text { ESBL producers } \\
(\mathbf{n = 1 5 2})\end{array}$} & \multicolumn{2}{c|}{$\begin{array}{c}\text { AmpC producers } \\
(\mathbf{n = 8})\end{array}$} \\
\cline { 2 - 5 } E.coli & No & $\%$ & No & 12.5 \\
\hline K.pneumoniae & 63 & 41.45 & 1 & 75 \\
\hline K.oxytoca & 25 & 16.45 & 1 & 12.5 \\
\hline P.mirabilis & 7 & 4.61 & - & - \\
\hline P.vulgaris & 18 & 11.84 & - & - \\
\hline E.aerogenes & 1 & 0.65 & - & 100 \\
\hline Total & 152 & 100 & 8 & \\
\hline
\end{tabular}


Chart.1 Culture positivity isolates $(\mathrm{n}=522)$

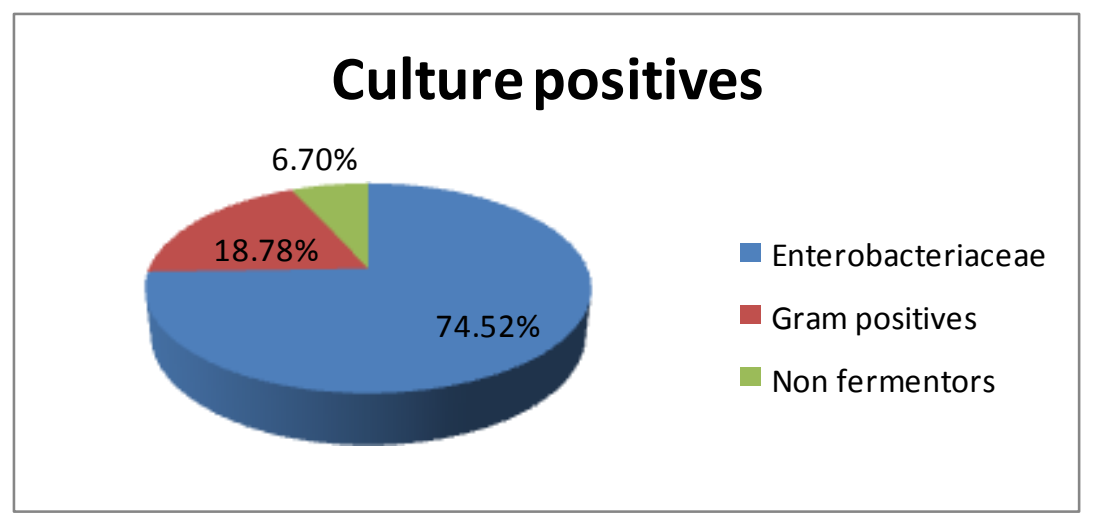

Chart.2 ESBL and AmpC producers among the Enterobacteriaceae isolates $(n=389)$

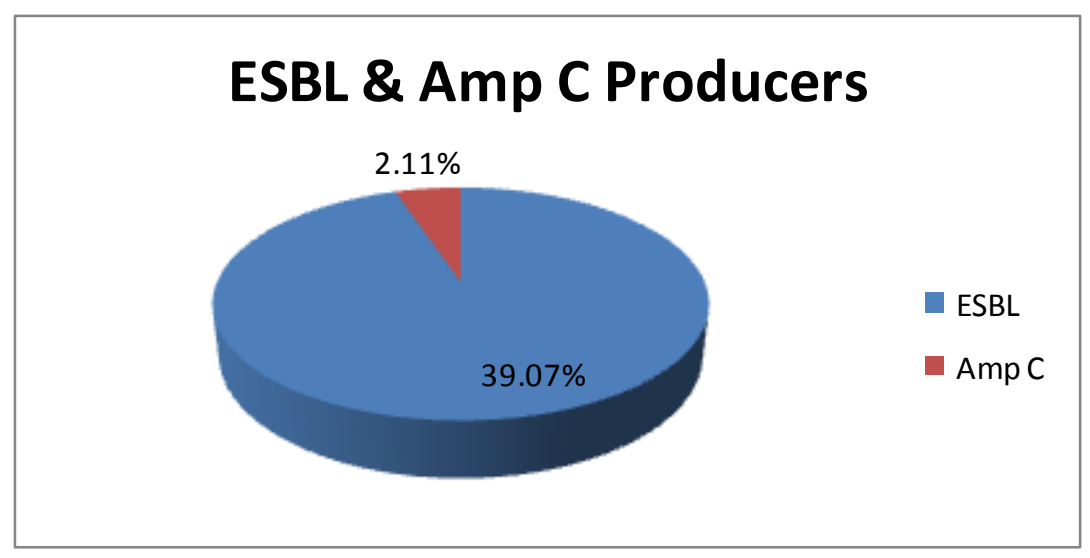

Chart.3 ESBL and AmpC producers among various clinical isolates $(\mathrm{n}=152)$




E.coli and Klebsiella species were the most common ESBL producing isolates $(41.45 \%$ each) in our study, followed by Proteus species $(16.45 \%)$. Similar results were obtained in the study conducted by Mita D. Wadekar et al., (2013) and Binita Bhuyan et al., (2018) who had revealed that 50\% and $21 \%$ respectively of their E.coli isolates were ESBL producers when compared to Klebsiella spp.(37.5\%, $16 \%$ respectively). Binita Bhuyan et al (2018) had also documented that $14.3 \%$ of their Proteus isolates were ESBL producers, which correlates well with our study.

In our current study about $8(2.11 \%)$ isolates were Amp C producers. Study conducted by Baha Abdalhamid et al., (2017) had documented that $1 \%$ of their Enterobacteriaceae isolates were Amp C beta lactamase producers whereas study conducted by Pankaj Baral et al., (2013) had revealed that about $27.8 \%$ of their Enterobacteriaceae isolates were AmpC producers whereas study by Ashish Jitendranath et al., (2018) had documented $11.2 \%$ of Enterobacteriaceae isolates as AmpC producers. This wide variation among the ESBL and AmpC producers among Enterobacteriaceae isolates were due to varying prevalence of site and type of infections among various hospitals.

Klebsiella species was the predominant AmpC $\beta$ lactamase producing agents $(87.5 \%)$ followed by E.coli (12.5\%). Similar results were shown in Ashish Jitendranath et al., (2018) study were $53.6 \%$ of AmpC producers belongs to Klebsiella spp. Followed by E.coli (21.4\%) and Enterobacter (14.3\%). Also Shubhdeep Kaur et al., (2016) in his study has shown that about $14.4 \%$ of Klebsiella species and $7.8 \%$ of E.coli isolates were Amp C producers.

Out of 152 ESBL isolates in our study, $60.53 \%$ were isolated from urine samples followed by pus samples (28.28\%). $75 \%$ of AmpC isolates were from urine samples and the rest of $25 \%$ of Amp C producers were from pus samples. Similar results have been obtained in the study conducted by Kumar MS et al., (2006) and Kritu panta et al., (2013), where nearly 54\% and $89.2 \%$ respectively of their ESBL and Multi drug resistant (MDR) isolates respectively were from urine samples. This high prevalence of ESBL and Ampc isolates among urine samples may be due to indiscriminate and over the counter use of antibiotics.

In conclusion, infectious diseases caused by various $\beta$-lactamases producing bacteria are emerging as a major threat to the public health. As ESBLs and AmpC producers are resistant to most of the second and third line antibiotics, it becomes increasingly mandatory to identify them, so that appropriate infection control measures can be ensured to prevent their emergence and spread, both in the hospital setup and also in the community. The general population and healthcare professionals should be educated about appropriate use of antibiotics which will help limit further spread of these multidrug resistant bacteria. Further periodic updates in the resistance pattern of these MDRs from time to time among different setups and areas, may pave way for formulating effective empirical therapy and in also addressing various problems associated with infections caused by MDRs.

\section{References}

Ashish Jitendranath, Vishnupriya Anoobis, Geetha Bhai, Ivy Vishwamohanan and J.T. Ramani Bai. Occurrence and Detection of AmpC $\beta$-Lactamases among Enterobacteriaceae in a Tertiary Care Centre in Trivandrum, India. Int.J.Curr.Microbiol.App.Sci (2018) 7(8): 176-181 
Binita Bhuyan, Pallabi Sargiary, Reema Nath. Study of Extended Spectrum Beta Lactamase and Metallo Beta Lactamase Production among Gram Negative Clinical Isolates from a Tertiary Care Hospital, North-East India. Int J Med Res Prof. 2018 July; 4(4); 64-68.

CLSI. Performance Standards for Antimicrobial Susceptibility Testing. 27th ed. CLSI supplement. M100. Wayne, PA: Clinical and Laboratory Standards Institute; 2017.

Kritu Panta, Prakash Ghimire, Shiba Kumar Rai, Reena Kiran Mukhiya, Ram Nath Singh, Ganesh Ra. Antibiogram typing of gram negative isolates in different clinical samples of a tertiary hospital. Asian J Pharm Clin Res, Vol 6, issue 1, 2013.153-156.

Kumar, MS, Lakshmi V, Rajagopalan R. Occurrence of extended spectrum beta-lactamases among Enterobacteriaceae spp. isolated at a tertiary care institute. Indian J Med Microbiol. 2006; 24(3): 208-211

Mita, D., Wadekar, K. Anuradha and D. Venkatesha. Phenotypic detection of ESBL and MBL in clinical isolates of Enterobacteriaceae. Int.J.curr.Res.Aca. Rev. 2013; 1(3): 89-95

Narinder Kaur, Amandeep Kaur and Satnam Singh. Prevalence of ESBL and MBL Producing Gram Negative Isolates from Various Clinical Samples in a Tertiary Care Hospital. Int.J.Curr.Microbiol.App.Sci (2017) 6(4): 1423-1430

Pankaj Baral, Sanjiv Neupane, Basudha Shrestha, Kashi Ram Ghimire,Bishnu Prasad Marasini, Binod Lekhak. Clinical and Microbiological observational study on AmpC $\beta$ lactamase producing Enterobacteriaceae in a Hospital of Nepal. The Brazilian journal of
Infectious diseases. Volume17, issue 2, March-April 2013, Pp. 256-259.

Pfeifer, Y., Cullik A, Witte W. Resistance to cephalosporins and carbapenems in Gram-negative bacterial pathogens. Int J Med Microbiol. 2010; 300(6):371-379.

Prevalence study of plasmid mediated AmpC beta lactamases in Enterobacteriaceae lacking inducible AmpC from Saudi hospitals. Baha Abdalhamid, Samar Albunayan, Alaa Shaikh, Nasreldin Elhadi, Reem Aljindan. Journal of Medical Microbiology 2017; 66: 1286-1290.

Randegge, R C., Boras A, Haechler H. Comparison of five different methods for detection of SHV extendedspectrum beta-lactamases. $\mathbf{J}$ Chemother. 2001; 13:24-33.

Rawat, D., Nair, D., Extended-spectrum $\beta$ lactamases in Gram Negative Bacteria. J Glob Infect Dis. 2010; 2:263-274.).

Rituparna Tewari, Susweta D. Mitra, Feroze Ganaie, Nimita Venugopal, Sangita Das, Rajeswari Shome, Habibur Rahman, Bibek R. Shome. 2018. Prevalence of extended spectrum âlactamase, AmpC â-lactamase and metallo $\quad \beta$-lactamase mediated resistance in Escherichia coli from diagnostic and tertiary healthcare centers in south Bangalore, India. Int J Res Med Sci. 2018 Apr; 6(4):13081313

Sanjo Gupta and Veena Maheswari. Prevalence of ESBLs among Enterobacteriaceae and their antibiotic resistance pattern from various clinical samples. Int.J.Curr.Microbiol.App.Sci (2017) 6 (9): 2620-2628.

Shubhdeep Kaur, Veenu Gupta and Deepinder china. AmpC $\beta$ lactamases producing Gram negative clinical isolates from a tertiary care hospital. J Mahatma Gandhi Inst Med Sci 2016; 
21: 107-10.

Tamang, MD., Nam, HN., Jang GC, Kim SR, Chae MH, Jung SC, et al. Molecular Characterization of ExtendedSpectrum- $\beta$-Lactamase-Producing and Plasmid-Mediated AmpC $\quad \beta$ Lactamase-Producing Escherichia coli Isolated from Stray Dogs in South Korea. Antimicrob Agents Chemother. 2012; 56: 2705-12.

Vercauteren, E., Descheemaeker, P., Ieven, M., Sanders CC, Goossens $\mathrm{H}$. Comparison of screening methods for detection of extended-spectrum beta- lactamases and their prevalence among blood isolates of Escherichia coli and Klebsiella spp. in a Belgian teaching hospital. J Clin Microbiol. 1997; 35: 2191-7.

Wondemagegn Mulu, Bayeh Abera and Dereje Abate. Bacterial agents and antibiotic resistance profiles of infections from different sites that occurred among patients of Debre Markos Referral Hospital, Ethiopia: a cross sectional study. BMC Res Notes. 2017; 10: 254.

\section{How to cite this article:}

Radhika Katragadda, Sowmya A. Venkateswaran and Padmakumari, J. 2019. A Study on Extended Spectrum Beta Lactamse and Amp C Beta Lactamse Producing Enterobacteriaceae Isolates from Various Clinical Samples in a Tertiary Care Hospital. Int.J.Curr.Microbiol.App.Sci. 8(05): 35-43. doi: https://doi.org/10.20546/ijcmas.2019.805.005 